\title{
Does Downloading PowerPoint Slides Before the Lecture Lead to Better Student Achievement?
}

Jennjou Chen and Tsui-Fang Lin

\begin{abstract}
With the availability of new information technology, PowerPoint presentations have been used extensively in classrooms for higher education, in addition to traditional chalk-and-talk presentations. However, their effectiveness is much less clear. The main purpose of this paper is to examine whether or not downloading PowerPoint slides before a class has any impact on students' learning outcomes for that class, using a panel data set. The estimation results show a nontrivial lecture slides effect. After controlling for students' unobserved individual heterogeneity and exam difficulty, downloading lecture slides before a class improves students' examination performance by 3.48 per cent. This finding suggests that instructors could help students improve their academic performance by supplying PowerPoint slides.
\end{abstract}

\section{Introduction}

With the availability of new information technology, PowerPoint presentations have been used extensively in classrooms for higher education, in addition to the traditional chalk-and-talk presentations. However, their effectiveness is unclear. For instance, some studies have found that students report positive attitudes about the course or perform better when instructors use PowerPoint presentations (Fifield and Peifer, 1994; Mantei, 2000; Bartscha and Cobern, 2003; Susskind, 2005) but others have reached different conclusions (Sosin et al., 2004).

The aim of this paper is to study whether downloading PowerPoint slides before attending a lecture has a positive effect on students' learning outcomes. Downloading of PowerPoint slides before a lecture might help students learn and 
perform better in examinations due to the following reasons. First, printed PowerPoint slides can be a good reference for students during a lecture. With printed slides at hand, students can preview class material if they want to. Also, during the class, students know what the teacher is covering and what will be covered next. Hence, downloading PowerPoint slides before a lecture might enhance students' comprehension of class materials, thereby enhancing or improving their learning.

Secondly, downloading PowerPoint slides can be beneficial to students in terms of better note-taking. Students in colleges are expected to take notes and review them while preparing for examinations. Many previous studies have suggested that the two frequently mentioned functions of note-taking - encoding and external storage (Di Vesta and Gray, 1972) - improve students' learning (Hartley, 1983; Kiewra, 1985; Kiewra and Benton, 1987; Kiewra et al., 1991). However, note-taking is not an easy task for students (Cohn et al., 1995). It is found that students' own notes are usually incomplete and inadequate for the purpose of review. Hence, an instructor's support to enhance students' ability to take notes in a more effective way could increase the effectiveness of the lectures. For instance, use of handouts, either in detailed format or partial outline style, is believed to produce a positive effect on students' academic performance (Hartley, 1976; Klemm, 1976; Kiewra, 1985). Since printed slides already contain course outline and important information, they can be viewed as outline style handouts. Therefore, students do not need to spend time replicating outlines; they can concentrate on listening and take better notes. As a consequence, downloading PowerPoint slides before a lecture might complement students' note-taking techniques and help them perform better in examinations.

The contribution of this study is to explore quantitatively, using a panel data approach, whether downloading PowerPoint slides before lectures has an impact on students' learning outcomes for those who attend classes. This issue has not been studied in prior literature. In addition, by employing a panel data set with a large number of observations, we are able to derive reliable estimates, after taking into account students' unobserved individual heterogeneity.

Ideally, a randomised experiment can be employed to study the effect of downloading PowerPoint slides on students' learning outcomes. For instance, students could be randomly divided into two groups, and students in only one group may be asked to download PowerPoint slides. We could then compare examination performance of the two groups and obtain the effect of downloading PowerPoint slides on their learning outcomes. However, this randomised experiment approach may not be feasible. First, it is not ethical for some students, 
selected randomly, not to receive PowerPoint slides, which may help their learning of the subject. Secondly, even if such an experiment could be conducted, it cannot be run repeatedly, from week to week, due to practical difficulties and the controversies it might create.

Instead of running a randomised experiment, we collect students' learning records and use statistical models to explore the impact of advance availability of PowerPoint slides on students' learning outcomes. During the study period, the instructor uploaded PowerPoint slides of the course on the university website three to five days before each class meeting. Whether or not students logged on to the course website and downloaded the slides before each class meeting is automatically recorded by the university e-learning server. This information on whether or not students downloaded course PowerPoint slides before attending classes provides a great opportunity for us to study the PowerPoint slides' effect.

It is to be noted that, in this analysis, we repeatedly observe students' behavior week-by-week. This enables us to use the variations exhibited by individual students (i.e. sometimes students download lecture slides but sometimes they do not) to identify the impact of using PowerPoint slides on their examination performance. Our estimation results show that downloading lecture PowerPoint slides before classes has a positive and significant impact on students' examination performance.

The rest of this paper is organised as follows. First, we explain our data and define the main variables. A statistical model used for our analysis is then described, followed by estimation results and finally a conclusion.

\section{Data}

We conducted a study of 126 students who took an intermediate microeconomics course at an elite public university in Taiwan, in the spring semester of 2007. Most sample students were sophomores, and majored in economics, when taking the course. The Economics Department offered three intermediate microeconomics courses during the sample semester; students were free to choose to register in any one. The sample class met at 9 a.m. and lasted for three hours. There were 12 three-hour class meetings during the sample period.

PowerPoint presentation was used in all lectures, and the slides were posted on the course website at least three to five days before each class meeting. The course website was located at the e-learning server provided and maintained by the university. Students were required to use their university email ID and password to log on to the server and obtain course related information. During the sample 
semester, around 25 per cent of the courses offered by the university had course specific websites on the e-learning server. The university e-learning server recorded students' use of these course specific websites.

We were able to gather information on when individual students logged on to the server, whether they visited a specific course website and, most importantly, which files were read or downloaded by each student. In this analysis, we define the main independent variable, download the PowerPoint slides, equal to one if a student downloaded lecture slides before a class. And, we let download the PowerPoint slides equal to zero if a student did not download lecture slides beforehand.

The dependent variable is students' performance in answering each examination question. Students' performance is measured by the percentage of correctness in each answer. The percentage of correctness of an answer is defined as credits awarded, divided by the maximum credits for that particular question. During the sample semester, there were three examinations, with a total of 40 questions. Three types of questions - multiple choice, short answer and short essay questions - were included in the examination papers. Each question may be weighted differently, and students can receive partial credits in case of short answer and short essay type questions.

Graph 1 depicts the percentage of students who downloaded lecture slides, weekly. In Week 1 , less than 10 per cent of students downloaded the lecture slides. This indicates the possibility of students' lack of information regarding the course website at the very beginning of the semester. In Week 5 , no student downloaded lecture slides because the instructor unintentionally forgot to upload the file before

Graph 1: Percentage of students who downloaded lecture slides before each class meeting (by week)

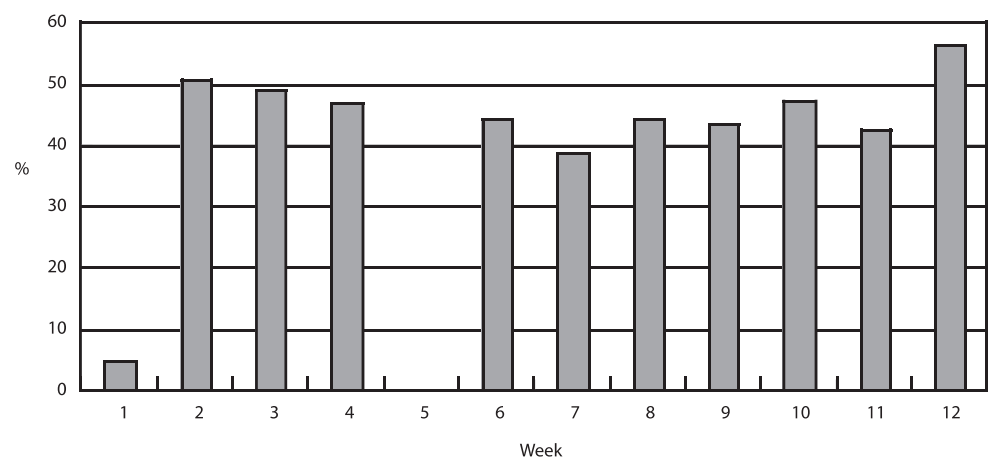


the class meeting. Other than that, on average, about 50 per cent of students downloaded lecture slides before class meetings.

In order to estimate the lecture slides' effect, we need to have within variations for each student in our data. Hence, we want to make sure that it is not the same 50 per cent of students downloading lecture slides every week. Graph 2 depicts the relationship between the number of students and the number of times the lecture slides were downloaded. From Graph 2, we find that some students downloaded slides only a few times, and some students downloaded more than half of the lecture slides. This suggests that the same group of students did not download lecture slides every week. Therefore, there do exist variations within in our sample and this allows us to identify the PowerPoint slides' effect.

Table 1 presents some simple statistics. On average, students downloaded lecture slides 5.1 times during the sample period. Senior students, relative to sophomore and junior students, downloaded lecture slides more frequently. Also, female students, relative to their male counterparts, downloaded lecture slides more frequently than others. Students who have better GPAs also downloaded lecture slides more frequently (than others). Students with below average family economic conditions downloaded lecture slides more frequently. We also observe that students who downloaded more lecture slides did perform better in examinations.

\section{Statistical models}

This study uses a micro level data set to explore the effect of downloading lecture PowerPoint slides before a class on attendees' examination performance. To obtain consistent estimates, we need to take into account whether or not downloading of lecture slides beforehand might be endogenous. Endogeneity here implies that

Graph 2: Frequency of downloading lecture slides

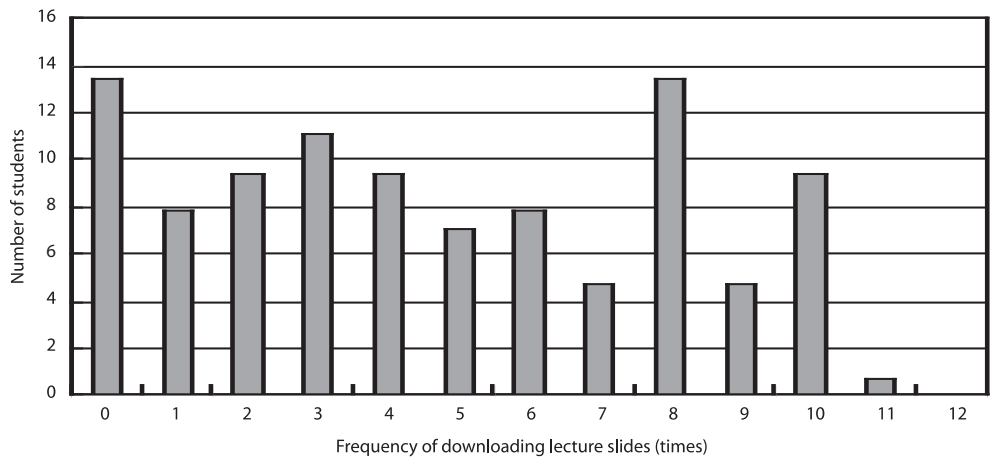


Table 1: Average Number of Times of Downloading Lecture Slides and Average Course Grades (by students' characteristics)

\begin{tabular}{|c|c|c|c|}
\hline & $\begin{array}{c}\text { Number } \\
\text { of } \\
\text { Students }\end{array}$ & $\begin{array}{l}\text { Average Number } \\
\text { of Times with } \\
\text { Downloaded } \\
\text { Lecture Slides }\end{array}$ & $\begin{array}{c}\text { Average } \\
\text { Course } \\
\text { Grade }\end{array}$ \\
\hline All Students & 126 & 5.127 & 65.62 \\
\hline \multicolumn{4}{|l|}{ Year of Study } \\
\hline Sophomore & 97 & 5.229 & 66.37 \\
\hline Junior & 24 & 4.583 & 62.21 \\
\hline Senior & 5 & 5.666 & 67.31 \\
\hline \multicolumn{4}{|l|}{ Gender } \\
\hline Female & 79 & 5.423 & 66.49 \\
\hline Male & 47 & 4.723 & 64.29 \\
\hline \multicolumn{4}{|l|}{ Average Grade Before } \\
\hline \multicolumn{4}{|l|}{ Entering the Course } \\
\hline above 90 & 0 & . & . \\
\hline $80-90$ & 59 & 6.135 & 69.27 \\
\hline $70-80$ & 47 & 4.341 & 61.32 \\
\hline $60-70$ & 7 & 2.428 & 56.84 \\
\hline below 60 & 8 & 3.125 & 63.96 \\
\hline \multicolumn{4}{|l|}{ Housing } \\
\hline Living with Relatives & 68 & 5.367 & 66.59 \\
\hline Not Living with Relatives & 57 & 4.912 & 64.56 \\
\hline \multicolumn{4}{|l|}{ Family Economic Condition } \\
\hline Poor & 0 & . & . \\
\hline Below Average & 11 & 6.001 & 64.91 \\
\hline Average & 96 & 5.125 & 66.48 \\
\hline Above Average & 18 & 4.833 & 61.73 \\
\hline Wealthy & 0 & . & . \\
\hline \multirow{2}{*}{\multicolumn{4}{|c|}{$\begin{array}{l}\text { Number of Times for } \\
\text { Downloading Lecture Slides }\end{array}$}} \\
\hline & & & \\
\hline $0-2$ times & 38 & 0.8421 & 63.95 \\
\hline 2-4 times & 22 & 3.409 & 60.49 \\
\hline $5-7$ times & 26 & 5.884 & 67.33 \\
\hline $8-10$ times & 27 & 8.962 & 68.31 \\
\hline $11-13$ times & 13 & 11.0700 & 70.16 \\
\hline
\end{tabular}


students who choose to download lecture slides may perform better in examinations due to their individual heterogeneity. For instance, students with strong motivation are more likely to download lecture slides beforehand, and their better performance in examinations could also be a result of their strong desire for learning. One solution to remedy this potential endogeneity problem is to use a panel data approach and employ the variations within each student to identify the lecture slides effect (i.e. the same student sometimes downloaded lecture slides but sometimes did not). To our knowledge, the panel data approach has been recently used to explore class attendance effects (Marburger, 2001, 2006; Stanca, 2006) but has never been used to study the lecture slides effect.

In this study, the instructor observes students' examination performance repeatedly and constructs a panel data set to investigate the lecture slides effect. As shown in Equation 1, we use a linear model to describe the relationship between a student's examination performance and various learning input variables. It is important to note that we restrict our sample to attendees for the following analysis.

$y_{i j}=\eta l_{i j}+\alpha_{i}+\gamma_{j}+\varepsilon_{i j}, \quad i=1,2, \ldots, I, j=1,2,3, \ldots, J$

$I$ is the total number of students and $J$ is the total number of examination questions. $y_{i j}$ corresponds to student $i$ 's observed examination performance on question $j$. As discussed in the data section, $y_{i j}$ represents the percentage correctness of each answer, which is defined as credits awarded divided by the maximum credits for the question. The variable of primary interest is the download the PowerPoint slides variable, $l_{i j}$. $l_{i j}$ equals one if student $i$ had downloaded lecture slides related to question $j$ before the corresponding lecture; $l_{i j}$ equals zero if student $i$ did not download lecture slides before the class meeting in which question $j$ was covered. $\eta$ represents the magnitude of the lecture slides effect. $\alpha_{i}$ represents student $i$ 's time-invariant individual effect; $\gamma_{j}$ represents the effect on answer to question $j$; and $\varepsilon_{i j}$ is a random disturbance term. It is important to note that some questions are covered in more than one lecture, and economic theories covered in a previous lecture may be used repeatedly later to analyse other issues. Therefore, students' past learning effort is expected to produce some effect on their examination performance. In this analysis, for simplicity, all the questions correspond to only one single, and the most relevant, lecture.

For the purpose of comparison, an ordinary least squares (OLS) method, a fixed effects method, and a random effects method are preformed to estimate the lecture slides effect. Our conclusions are based on estimates from the fixed effects model, since OLS and random effects models both potentially suffer form the endogeneity problem (i.e. whether downloading of lecture slides and individual effects are correlated, or $\left.\operatorname{cov}\left(l_{i j}, \alpha_{i}\right) \neq 0\right)$. 


\section{Estimation results}

Table 2 presents the estimation results of the lecture slides effect. The first column presents the results of the OLS model, the second column presents the results of the fixed effects model, and the third column presents the results of the random effects model.

The coefficients of download the PowerPoint slides in three models are all statistically significantly different from zero. The marginal effects of downloading lecture slides are 4.61 per cent and 4.17 per cent for OLS and random effects models, respectively. The value declines to 3.48 per cent in the fixed effects model. As discussed before, students who download lecture slides more frequently may have stronger motivations to study, and thus perform better in examinations. Hence, with the potential existence of unobserved student heterogeneity, part of the 4.61 per cent improvement in examination performance for OLS results (or 4.17 per cent for random effects) may be an overestimate of the lecture slides effect. As expected, after accounting for individual time-invariant heterogeneity in the fixed effects model, we obtain a smaller lecture slides effect, i.e. 3.48 per cent. The fixed effects model solves part of the endogeneity problem by using within variations for each student.

From the above, we have found that downloading lecture slides has produced a significant and positive effect on students' examination performance. However, the question is whether a 3.48 per cent improvement in grades can be deemed to be a big effect. In order to be able to answer this question, we need to have some concrete ideas about the magnitude of the lecture slides effect. Hence, we estimate an average class attendance effect, using the current data set, and then compare

Table 2: Estimation Results of the Lecture Slides Effect

\begin{tabular}{lccc}
\hline & OLS & Fixed Effects & Random Effects \\
\hline Dependant Variable & Correctly Answer the Question $(\%$, between 0 and 1) \\
Independent Variable & & & \\
Download the PowerPoint Slides & $0.0461^{* *}$ & $0.0348^{* *}$ & $0.0417^{* *}$ \\
& $(0.0127)$ & $(0.0165)$ & $(0.0147)$ \\
R-squared & 0.3072 & 0.3807 &. \\
Sample Size & 3,675 & 63,675 & 63,675 \\
\hline
\end{tabular}

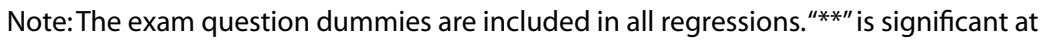
0.05 Type I error level. White (1980) robust standard errors are in parentheses. 
the magnitude of the average class attendance effect and that of lecture slides effect. The approach used to estimate the average class attendance effect is similar to the one in previous literature (Marburger, 2001,2006; Stanca, 2006). For our sample, the average attendance effect from a fixed effects model is 2.62 per cent. This estimation suggests that, for this group of students, the grade improvement because of downloading lecture slides is even greater than the grade improvement because of attending a lecture. Hence, we contend that the magnitude of the lecture slides effect is not trivial at all.

\section{Conclusion}

This study contributes to the literature by exploring the link between downloading PowerPoint slides before classes and students' learning outcomes. The effects of using downloaded lecture slides on students' academic performance are statistically significant across models. Our estimation results have shown that downloading lecture PowerPoint slides before classes improves students' examination performance by 4.62 per cent in the least squares model. In addition, after controlling for individual heterogeneity, downloading lecture PowerPoint slides before classes still enhances students' examination performance by 3.48 per cent. Also, for this group of students, the lecture slides effect has been found to be greater than the average attendance effect. In light of the statistically significant and non-trivial effect of downloading lecture PowerPoint slides before classes on students' examination performance, we suggest that instructors could help students improve their learning outcomes by supplying lecture PowerPoint slides before classes.

\section{Notes}

The authors thank Li-Hsuan Huang, Chih-Chiang Hsu, P.C. Roger Cheng, and two anonymous referees for their thoughtful comments.

\section{References}

Bartscha, A. R. and K. M. Cobern (2003) 'Effectiveness of PowerPoint Presentations in Lectures', Computers \& Education 41(1): 77-86.

Cohn, E., S. Cohn and J. Bradley Jr. (1995) 'Notetaking, Working Memory, and Learning in Principles of Economics', Journal of Economic Education 26(4):291-307.

Di Vesta, F. J. and G. S. Gray (1972) 'Listening and Note Taking', Journal of Educational Psychology 63(1): 8-14.

Fifield, S. and R. Peifer (1994) `Enhancing Lecture Presentations in Introductory Biology with Computer-based Multimedia', Journal of College Science Teaching 23(4): 235-9. Hartley, J. (1976) 'Lecture Handouts and Student Notetaking', Programmed Learning and Educational Technology 13(2): 58-64. 
Hartley, J. (1983) 'Note-Taking Research: Resetting the Scoreboard', Bulletin of the British Psychological Society 36: 13-14.

Kiewra, K. A. (1985) 'Students' Note-taking Behaviors and the Efficacy of Providing the Instructor's Notes for Review', Contemporary Educational Psychology 10:378-86.

Kiewra, K. A. and S. L. Benton (1987) 'The Relationship between Information Processing Ability and Notetaking', Contemporary Educational Psychology 13:33-44.

Kiewra, K. A., N. F. Dubois, D. Christian, A. McShane, M. Meyerhoffer and D. Roskelley (1991) 'Note-taking Functions and Techniques', Journal of Education Psychology 83(2): 240-5.

Klemm, W. R. (1976) 'Efficiency of Handout “Skeleton” Notes in Student Learning,' Improving College and University Teaching 24:10-12.

Mantei, E. J. (2000) 'Using Internet Class Notes and PowerPoint in the Physical Geology Lecture', Journal of College Science Teaching, 29(1): 2-6.

Marburger, R. (2001) 'Absenteeism and Undergraduate Exam Performance', Journal of Economic Education 32 (2): 99-110.

Marburger, R. (2006) ‘Does Mandatory Attendance Improve Student Performance?', Journal of Economic Education 37(2): 148-55.

Sosin K., B. J. Blecha, R. Agarwal, R. L. Bartlett and J. I. Daniel (2004) 'Efficiency in the Use of Technology in Economic Education: Some Preliminary Results', American Economic Review 94(2): 253-8.

Stanca, L. (2006) 'The Effects of Attendance on Academic Performance: Panel Data Evidence for Introductory Microeconomics', Journal of Economic Education 37(4): 251-66.

Susskind, E. J. (2005) 'PowerPoint's Power in the Classroom: Enhancing Students' Self-efficacy and Attitudes', Computers \& Education 45(2): 203-15.

White, H. (1980) 'A Heteroskedasticity-consistent Covariance Matrix Estimator and a Direct Test for Heteroskedasticity', Econometrica 48(4): 817-38.

\section{Contact details}

Jennjou Chen

Department of Economics

National Chengchi University

Taipei City, 11605

Taiwan

Tsui-Fang Lin

Department of Public Finance

National Taipei University

Taipei City, 10478

Taiwan 